\title{
LEVANTAMENTO FITOSSOCIOLÓGICO DE PLANTAS DANINHAS EM CULTIVO DE GENÓTIPOS DE BATATA-DOCE
}

\author{
Jair Tenório Cavalcante ${ }^{1}$, Paulo Vanderlei Ferreira', Jorge Luiz Xavier Lins Cunha², Moisés Tiodoso da Silva ${ }^{3}$, \\ Islan Diego Espindula de Carvalho ${ }^{4 *}$, Reinaldo Alencar Paes ${ }^{1}$
}

\author{
1 Professor Dr., Centro de Ciências Agrárias (CECA), Universidade Federal de Alagoas (UFAL), BR 104 Norte, Km 85, Rio Largo, AL. \\ CEP 57.000-100. \\ 2Pesquisador Dr., Centro de Ciências Agrárias (CECA), Universidade Federal de Alagoas (UFAL), BR 104 Norte, Km 85, Rio Largo, AL. \\ CEP 57.000-100 \\ 3Mestrando em Agronomia (PPGA), Centro de Ciências Agrárias (CECA), Universidade Federal de Alagoas (UFAL), BR 104 Norte, Km \\ 85, Rio Largo, AL. CEP 57.000-100 \\ 4 Doutorando em Agronomia (PPGAMGP), Universidade Federal Rural de Pernambuco (UFRPE), R. Manuel de Medeiros, s/n - Dois \\ Irmãos, Recife - PE, 52171-900 \\ *Autor para correspondência: Islan Diego Espindula de Carvalho, iislandiego@hotmail.com
}

RESUMO: Este trabalho teve como objetivo identificar e quantificar a comunidade populacional de plantas daninhas presentes no cultivo de três genótipos de batata-doce. $O$ ensaio foi realizado, na área experimental do Setor de Melhoramento Genético de Plantas do Centro de Ciências Agrárias da Universidade Federal de Alagoas (SMGP/CECA/UFAL), município de Rio Largo, no período de abril a setembro de 2013. Utilizou-se o delineamento em blocos casualizados no esquema fatorial $3 \times 14$ com três repetições, sendo três genótipos de batata-doce (variedade Sergipana e os clones 6 e 14) e 14 períodos de interferência, (sete períodos de controle, a partir dos quais as plantas daninhas eram controladas, e sete períodos de convivência entre a comunidade infestante e os genótipos da cultura da batata-doce, onde as espécies infestantes emergidas após esses intervalos não eram mais controladas). As espécies de plantas daninhas foram coletadas através de um quadrado amostral com 0,50 m x 0,50 m, onde foram seccionadas ao nível do solo antes de cada capina e na ocasião da colheita. Após identificadas e quantificadas foram levadas à estufa com circulação forçada $65^{\circ} \mathrm{C}$ para determinação da massa seca. As principais plantas daninhas presentes na área do experimento em todos os genótipos estudados foram: Poaia branca (Richardia brasiliensis Gomes), Mentrasto (Ageratum conyzoides L.), Capim-pé-de-galinha (Eleusine indica (L.) Gaertn.), Mussambê (Cleome affinis DC.), Tiririca-de-brejo (Cyperus iria), Maria Pretinha (Solanum americanum Mill.), Capim tapete (Mollugo verticillata L.) e Capim Colchão (Digitária horizontalis Willd.). PALAVRAS-CHAVE: Ipomoea batatas (L.) Lam., período crítico, controle e convivência.

\section{POPULATION SURVEY OF WEEDS IN CULTIVATION OF SWEET POTATO GENOTYPES}

ABSTRACT: This work aimed to identify and quantify the weed population community present in the cultivation of three sweet potato genotypes. The experiment was carried out in the Experimental Area of the Setor de Melhoramento Genético de Plantas of the Centro de Ciências Agrárias of the Universidade Federal de Alagoas (SMGP-CECA-UFAL), municipality of Rio Largo, from April to September 2013. It was used The randomized block design in the $3 \times 14$ factorial scheme with three replicates, three sweet potato genotypes (Sergipana variety and clones 6 and 14) and 14 interference periods (seven control periods, from which plants Were weeded, and seven periods of coexistence between the weed community and the sweet potato genotypes, where weed species emerged after these intervals were no longer controlled). The weed species were collected through a sample square with $0.50 \mathrm{~m} \times 0.50 \mathrm{~m}$, where they were sectioned at the level of the soil before each weeding and at the time of harvest. After being identified and quantified, they were taken to the oven with forced circulation $65^{\circ} \mathrm{C}$ to determine the dry mass. The main weeds present in the experimental area in all the genotypes studied were: Poaia branca (Richardia brasiliensis Gomes), Mentrasto (Ageratum conyzoides L.), Pé de galinha (Eleusine indica (L.) Gaertn.), Mussambe (Cleome affinis DC), Tiririca-de-brejo (Cyperus iria), Maria Pretinha (Solanum americanum Mill.), Capim tapete (Mollugo verticillata L.) and Capim colçhão (Digitária horizontalis Willd.).

KEYWORDS: Ipomoea batatas (L.) Lam; critical period, control and coexistence. 


\section{INTRODUÇÃO}

A cultura da batata-doce (Ipomoea batatas (L.) Lam) é uma espécie que pertence à família da convolvulácea, originária das Américas Central e do Sul. Apresenta custo de produção relativamente baixo, com investimentos mínimos, e bom retorno econômico. É também uma das hortaliças com maior capacidade de produzir energia por unidade de área e tempo (Embrapa, 2009). Esta cultura é disseminada na maioria das regiões brasileiras, apresentando relevância econômica e de ampla aceitação popular (Filgueira, 2008).

O maior produtor mundial de batata-doce é a China, com produções de 118 milhões de toneladas em uma área de 6 mil hectares e rendimentos médios em torno de $20 \mathrm{t} \mathrm{ha}^{-1}$. No Brasil, às safras tem alcançado bons índices, de produtividade, em 2014 obteve uma produtividade de 13,2 tha $^{-1}$ e, em 2015 uma produtividade de 13,6 $\mathrm{t} \mathrm{ha}^{-1}$, esses números revelam, sobretudo, as mudanças sofridas pelo sistema de produção, o que indica evolução do nível tecnológico (Anuário Brasileiro de Hortaliças, 2013). Em Alagoas a área cultivada de aproximadamente 1.552 ha, com produção de 13,729 toneladas apresentando rendimento baixo, em média 8,85 t ha $^{-1}$, sendo o município de Feira Grande o maior produtor com cerca de 700 ha e produção de 6.300 toneladas com rendimento de 9,0 t ha- $^{-1}$ (IBGE, 2013).

Vários os aspectos prejudicam o desempenho da cultura da batata-doce no território nacional, dentre eles destacam-se as práticas culturais obsoletas e uso de cultivares inadequadas para a região (Anuário Brasileiro de Hortaliças, 2013). Estudos sobre seleção de clones de batata-doce vêm sendo desenvolvidos pelo Setor de Melhoramento Genético do Centro de Ciências Agrárias da Universidade Federal de Alagoas (SMGP-CECA-UFAL) em alguns municípios no estado, visando à obtenção de variedades superiores, cujos resultados preliminares indicam a existência de materiais genéticos distintos e com potenciais para 0 cultivo na região.

Entre os fatores limitantes que interferem negativamente na produtividade pode-se destacar a competição da batata-doce com as plantas daninhas, essas reduzem a produtividade de acordo com a densidade populacional e as espécies infestantes, com isso se faz necessária a identificação das espécies que competem com a batata-doce para contribuir na escolha do melhor método de controle e o período em que o controle será realizado (Cavalcante et al., 2017).
Diante disso, o presente trabalho teve como objetivo identificar e quantificar a comunidade populacional de plantas daninhas presentes na área de cultivo de três genótipos de batata-doce.

\section{MATERIAL E MÉTODOS}

O ensaio foi conduzido no período de abril a setembro de 2013, na área experimental do Setor de Melhoramento Genético de Plantas do Centro de Ciências Agrárias da Universidade Federal de Alagoas (SMGP-CECA/UFAL), localizado no Campus Rio Largo, BR 104 Norte, km 85, Rio Largo - Alagoas, com latitude de 9 o 27' S, longitude de 35027 ' W e uma altitude de 127 m, (Centeno et al.,1994).

$\mathrm{Na}$ área experimental foram retiradas amostras de solo para análise química e física, através de uma sonda a uma profundidade de $25 \mathrm{~cm}$ de profundidade percorrendo a área em zig-zag e encaminhadas ao Laboratório para análise.

Os dados meteorológicos referentes à pluviosidade e temperatura, foram coletados através da Estação Agrometeorológica do CECA/UFAL - Rio Largo - AL, com pluviosidade acumulada durante o ciclo da cultura de $1192,8 \mathrm{~mm}$ e temperatura média de $24^{\circ} \mathrm{C}$.

Utilizou-se o delineamento experimental em blocos casualizados no esquema fatorial $3 \times 14 \mathrm{com}$ três repetições, sendo três genótipos de batata-doce (variedade Sergipana, uma das mais cultivada no Estado, mantida no banco de germoplasma do referido setor, e clones 6 e 14, ambos obtidos SMGP-CECA/ UFAL, sendo o clone 06 , proveniente da cultivar " 60 Dias" e o clone 14 da cultivar "Roxa de Rama Fina"; e 14 períodos de interferências.

Os períodos de interferências foram constituídos de sete períodos de controle $(0,10,20$, $30,40,50,60$ dias após o plantio - DAP), a partir dos quais as plantas daninhas eram controladas por meio de capinas manuais e a enxada, e de sete períodos de convivência $(0,10,20,30,40,50,60$ - DAP) entre a comunidade infestante e a cultura, onde as espécies infestantes emergidas após esses intervalos não foram mais controladas.

As parcelas experimentais foram constituídas por quatro leiras de $5,0 \mathrm{~m}$ de comprimento com 0,30 m de altura cada, com 12 plantas por leira, no espaçamento de $0,80 \times 0,40 \mathrm{~m}$, totalizando 24 plantas, sendo considerada como área útil as duas leiras 
centrais deixando as duas plantas da cabeceira de cada leira como bordadura.

O preparo do solo da área experimental foi realizado com uma aração, duas gradagens cruzadas e sulcamento para formação das leiras; a adubação mineral recomendada foi aplicada em covas com $0,15 \mathrm{~m}$ de profundidade abertas no topo da leira entre as plantas e cobertas, de acordo com as recomendações das análises (Tabela 1) e das exigências da cultura, utilizando-se $140 \mathrm{~kg} \mathrm{ha}^{-1}$ de $\mathrm{N}, 20 \mathrm{~kg} \mathrm{ha}^{-1}$ de $\mathrm{P}_{2} \mathrm{O}_{5}$ e $50 \mathrm{~kg} \mathrm{ha}^{-1}$ de $\mathrm{K}^{2} \mathrm{O}$, na forma de sulfato de amônio, superfosfato simples e cloreto de potássio, respectivamente; o plantio foi realizado utilizando ramas novas com 90 dias de idade, sadias, com 8 a 10 entrenós, dos quais 3 a 4 foram enterrados no topo da leira a $0,10 \mathrm{~m}$ de profundidade e espaçadas de $0,40 \mathrm{~m}$; e durante o período compreendido entre o plantio até a colheita, foram realizados os tratos culturais necessários: irrigação por aspersão sendo aplicado durante todo o ciclo da cultura $520 \mathrm{~mm}$, para suprir a irregularidades das chuvas na região, amontoa, controle de pragas e adubação de cobertura de acordo com a recomendação. A colheita dos tubérculos foi efetuada aos 130 dias após o plantio.

Tabela 1. Espécies de plantas daninhas coletadas ao final de cada período de convivência nos tratamentos com períodos iniciais de controle de plantas daninhas e na época da colheita na cultura da batata-doce

\begin{tabular}{|c|c|c|}
\hline Família & Nome botânico & Nome comum \\
\hline Poaceae & Brachiaria mutica (Forssk.) Staf & Capim-de-planta \\
\hline Poaceae & Cenchrus echinatus L. & Capim-carrapicho \\
\hline Poaceae & Digitária horizontalis Willd. & Capim colchão \\
\hline Poaceae & Eleusine indica (L.) Gaertn. & Capim-pé-de-galinha \\
\hline Asteraceae & Acanthospermum hispidum DC. & Carrapicho-de-carneiro \\
\hline Asteraceae & Ageratum conyzoides $\mathrm{L}$. & Mentrasto \\
\hline Asteraceae & Emilia fosbergii Nicolson & Falsa serralha \\
\hline Asteraceae & Galinoga parviflora Cav. & Picão branco \\
\hline Fabaceae & Calopogonium mucunoides Des. & Calopogônio \\
\hline Fabaceae & Desmodium tortuosum (Sw.) DC. & Carrapicho-beiço-de-boi \\
\hline Solanaceae & Physalis angulata L. & Balão \\
\hline Solanaceae & Solanum americanum Mill. & Maria pretinha \\
\hline Cyperaceae & Cyperus iria L. & Tiririca-de-brejo \\
\hline Cyperaceae & Cyperus suculento L. & Junça \\
\hline Euphorbiaceae & Chamaesyce hyssopifolia (L.) Small & Erva-de-santa-luzia \\
\hline Euphorbiaceae & Croton lobatos L. & Erva-de-rola \\
\hline Amarantaceae & Amaranthus deflexus $\mathrm{L}$. & Caruru \\
\hline Brassicaceae & Cleome affinis DC. & Mussambê \\
\hline Convovulaceae & Merremia cissoids (L.) Hallier f. & Jitirana \\
\hline Phyllanthaceae & Phyllanthus tenellus Roxb. & Quebra-pedra \\
\hline Molluginaceae & Mollugo verticillata $L$. & Capim tapete \\
\hline Rubiaceae & Richardia brasiliensis Gomes & Poaia branca \\
\hline Turneraceae & Turnera ulmifolia L. & Xanana \\
\hline Portulacaceae & Portulaca oleraceae L. & Beldroega \\
\hline Scrophulariaceae & Lindernia crustaceae (L.) F. Muell & Douradinha-do-pará \\
\hline Boraginaceae & Heliotropium indicum L. & Crista-de-galo \\
\hline
\end{tabular}

A avaliação da comunidade de plantas convivência $(10,20,30,40,50,60,70$ e 130 DAP), para daninhas foi realizada ao final de cada período de os tratamentos com períodos iniciais de controle de 
plantas daninhas e aos 130 DAP para os tratamentos que permaneceram com presença de plantas daninhas, determinando a densidade e a massa seca dessas espécies encontradas. Foi utilizado como unidade amostral um quadrado de metal $(0,50 \times 0,50 \mathrm{~m})$, o qual foi lançado de forma aleatória uma única vez na área útil de cada parcela. Em cada quadro amostrado, as plantas daninhas foram coletadas (interseccionadas rente ao solo) e identificadas quanto à família, espécie e nome vulgar, determinando o número de indivíduos. Logo após as plantas amostradas foram alocadas em sacos de papel e levadas para estufa de circulação forçada de ar a $65^{\circ} \mathrm{C}$ até obtenção da massa constante (72 h), obtendo-se com o auxílio de uma balança de precisão (Quimis - GB 2000) a massa da matéria seca da parte aérea da comunidade infestante.

A identificação da comunidade infestante de plantas daninhas foi realizada seguindo as instruções de Lorenzi (2006), e em seguida foram calculadas as seguintes variáveis fitossociológicas: densidade (D), densidade relativa $(\mathrm{Dr})$, freqüência $(F)$, freqüência relativa $(\mathrm{Fr})$, abundância $(\mathrm{A})$, abundância relativa $(\mathrm{Ar})$ e índice de importância relativa (Ir), massa seca da parte aérea e frequência, as quais foram utilizadas para obtenção do índice de valor de importância (IVI) das plantas daninhas calculado conforme a fórmula proposta por Mueller-Dombois e Ellemberg (1974).

\section{$\mathrm{IVI}=\mathrm{DR}+\mathrm{FR}+\mathrm{DoR}$}

Onde:

IVI- representa o índice de valor de importância;

DR- é a densidade relativa de cada espécie (razão entre o número de plantas de uma espécie e o total de plantas amostradas, expresso em porcentagem);

FR- representa a freqüência relativa (freqüência em que a espécie ocorreu nas amostragens, expressa em porcentagem) e;

DoR- é a dominância relativa (razão entre massa seca da espécie e o total de massa seca amostrado, expresso em porcentagem).

Procedeu-se o cálculo da importância relativa (IR), utilizando também a fórmula proposta por MuellerDombois e Ellemberg (1974). A IR é determinada por meio da razão entre o IVI de cada espécie pela somatória dos IVIs de todas as espécies, expresso em porcentagem $(\mathrm{IR}=\mathrm{IVI} / / \mathrm{VI} \mathrm{s})$.
Todos os dados foram submetidos a Análise de Variância, utilizando o nível de $5 \%$ de significância. A densidade e biomassa das plantas daninhas foram submetidos a análise regressiva e adaptadas ao modelo não-linear Sigmoidal de Boltzman, utilizando programas estatísticos, conforme Kuva et al. (2003).

\section{RESULTADOS E DISCUSSÕES}

\section{Caracteres relacionados às plantas daninhas:}

A comunidade infestante de plantas daninhas foi composta por 26 espécies, entre dicotiledôneas e monocotiledôneas, distribuídas em 14 famílias, sendo: quatro Poaceae, quatro Asteraceae, duas Fabaceae, duas Solonaceae, duas Cyparaceae, duas Euphorbiaceae e as demais: Amarantaceae, Brassicaceae, Convovulaceae, Phyllanthaceae, Molluginaceae, Rubiaceae, Turneraceae, Portulacaceae, Scrophulariaceae, e Boraginaceae com apenas um representante (Tabela1).

\section{Densidade}

As espécies de plantas daninhas que se destacaram com relação à densidade total foram: Poaia branca (Richardia brasiliensis Gomes), Capimpé-de-galinha (Eleusine indica (L.) Gaertn.), Mentrasto (Ageratum conyzoides L.), Mussambê (Cleome affinis DC.), Tiririca-de-brejo (Cyperus iria L.), Capim tapete (Mollugo verticillata L.), Maria Pretinha (Solanum americanum Mill.) e Capim Colchão (Digitária horizontalis Willd.).

As maiores densidades de plantas daninhas foram atingidas no período de 20 a 50 dias após 0 plantio (DAP) nas áreas das parcelas cultivadas com o Clone 6 e a variedade Sergipana e de 20 a 40 DAP nas áreas das parcelas com o Clone 14, sendo que a maior densidade foi atingida aos 30 DAP na área com a variedade Sergipana com 741,33 plantas $\mathrm{m}^{-2}$, e no período de 20 a 30 DAP nas parcelas com o Clone 6 com 644,00 e 622,67 plantas $\mathrm{m}^{-2}$ respectivamente e com o Clone 14 com 680,00 e 648,25 plantas m $^{-2}$ respectivamente. As menores densidades de plantas daninhas ocorreram aos 10 DAP, tanto para as áreas das parcelas com o Clone 6, com 106,67 plantas $\mathrm{m}^{-2}$, quanto para as áreas das parcelas com o Clone 14 com 117,33 plantas $\mathrm{m}^{-2}$, e aos 130 DAP nas áreas das parcelas com a variedade Sergipana com 129,37 plantas $\mathrm{m}^{-2}$ (Figura 1). 
Figura 1. Densidade total das plantas daninhas infestantes (plantas $\mathrm{m}^{-2}$ ) em função dos períodos de convivência com genótipos de batata-doce em dias após o plantio (DAP). Rio Largo - AL, 2013.

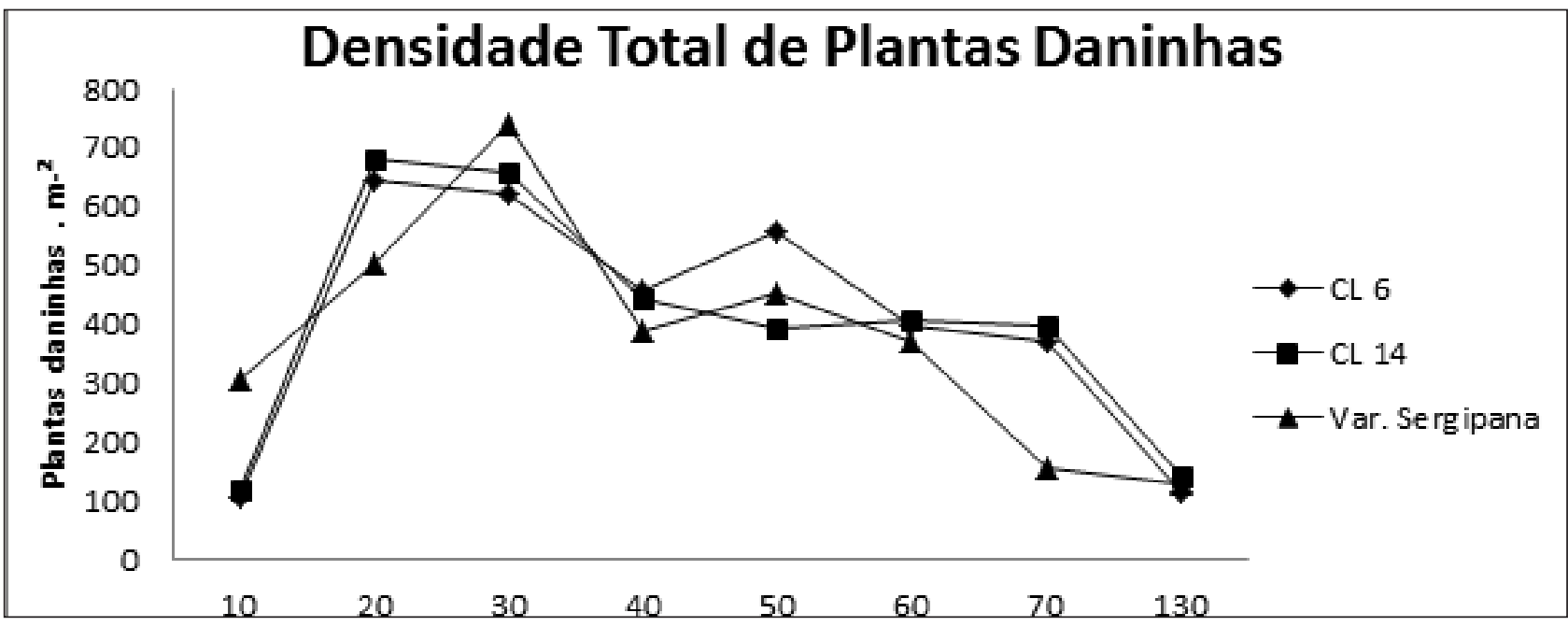

A partir dos 50 DAP, verificou-se redução na densidade populacional das plantas infestantes nas parcelas cultivadas com a variedade Sergipana e - Clone 6, e só aos 70 DAP nas parcelas cultivadas com o Clone 14, devido à senescência de algumas espécies de plantas daninhas anuais de ciclo curto, além daquelas que possuem como característica porte elevado e hábito de crescimento trepador. Além disso, a baixa densidade de plantas infestantes proporcionou uma maior disponibilidade de recursos naturais (água, luminosidade nutrientes e etc.), permitindo o surgimento de novos indivíduos, que se desenvolveram, aumentando a massa seca das plantas daninhas, acumulada ao longo do ciclo da cultura. Resultados semelhantes foram encontrado por Freitas et al. (2009), que trabalhando com interferência de plantas daninhas na cultura da cenoura, mostraram que a redução do número de plantas, verificada no final do ciclo da cultura, se deve à predominância de plantas anuais com ciclo curto, que entraram em senescência no final do período experimental, e, principalmente, à competição exercida pelas espécies dominantes, com alta taxa de crescimento inicial e com maior estatura, como Amaranthus spinosus, que, mesmo com 11,30\% da densidade total, foi responsável por mais de $55 \%$ da massa seca total das plantas daninhas.

Costa et al. (2008), estudando os períodos de interferência de plantas daninhas na cultura da batata (Solanum tuberosum), verificaram que as maiores densidades de plantas daninhas foi a partir dos 14 DAP (249 plantas $\mathrm{m}^{-2}$ ) e aos 28 DAP (433 plantas $\mathrm{m}^{-2}$ ) para períodos de controle e convivência, respectivamente. Por outro lado, Freitas et al. (2009), avaliando a interferência de plantas daninhas na cultura da cenoura, observaram os maiores valores de densidade de plantas daninhas entre os 21 (1.194 plantas $\mathrm{m}^{-2}$ ) e 24 (1.164 plantas $\mathrm{m}^{-2}$ ) dias após a emergência (DAE), para os períodos iniciais de controle. Coelho et al. (2009), estudando interferência de plantas daninhas na cultura da cenoura, observaram que o primeiro período de maior emergência das plantas daninhas foi aos 14 DAS (728 plantas $\mathrm{m}^{-2}$ ) e um segundo aos 42 DAS (1.324 plantas $\left.\mathrm{m}^{-2}\right)$, onde em ambas as épocas, $A$. conyzoides apresentava alta importância relativa, permitindo que a espécie dominasse a comunidade. Costa et al. (2013), avaliando períodos de interferências das plantas daninhas na cultura da mandioca "fécula branca" verificaram que as maiores densidades das plantas daninhas foram atingidas aos $150 \mathrm{DAP}\left(50\right.$ plantas $\mathrm{m}^{-2}$ ) e aos 75 DAP (114 plantas $\mathrm{m}^{-2}$ ), para os períodos de controle e de convivência, respectivamente.

Das espécies de plantas daninhas observadas nas parcelas cultivadas com a variedade Sergipana, o Mentrasto ( $A$. conyzoides L.), apresentou maior densidade com 293,33 plantas $\mathrm{m}^{-2}$ aos 30 DAP; seguido pela Poaia branca (R. brasiliensis Gomes), com 150,67 plantas $\mathrm{m}^{-2}$ aos 50DAP; Capim-pé-de-galinha ( $E$. indica (L.) Gaertn.), com 94,67 plantas $\mathrm{m}^{-2}$ aos 20 e 93,33 plantas $\mathrm{m}^{-2}$ aos 30 DAP; Tiririca de brejo (C. iria L.), com 72,00 plantas $\mathrm{m}^{-2}$ aos 30 e 73,33plantas $\mathrm{m}^{-2}$ aos 60 DAP; Capim Colchão (D. horizontalis Willd.) com 40,00 plantas $\mathrm{m}^{-2}$ aos 30 DAP; Capim tapete (M. verticillata L.), com 37,33 plantas $\mathrm{m}^{-2}$ aos 30 DAP, Mussambê (C. affinis DC.) com 29,33 plantas $\mathrm{m}^{-2}$ aos 30 DAP e Maria Pretinha (S. americanum Mill.) com 24,00 plantas $\mathrm{m}^{-2}$ aos 20 DAP. (Figura 2). 
Figura 2. Densidade total e densidade das principais plantas daninhas infestantes (plantas $m-2$ ) em função dos períodos de convivência com a variedade de batata-doce Sergipana em dias após o plantio (DAP). Rio Largo - AL, 2013.

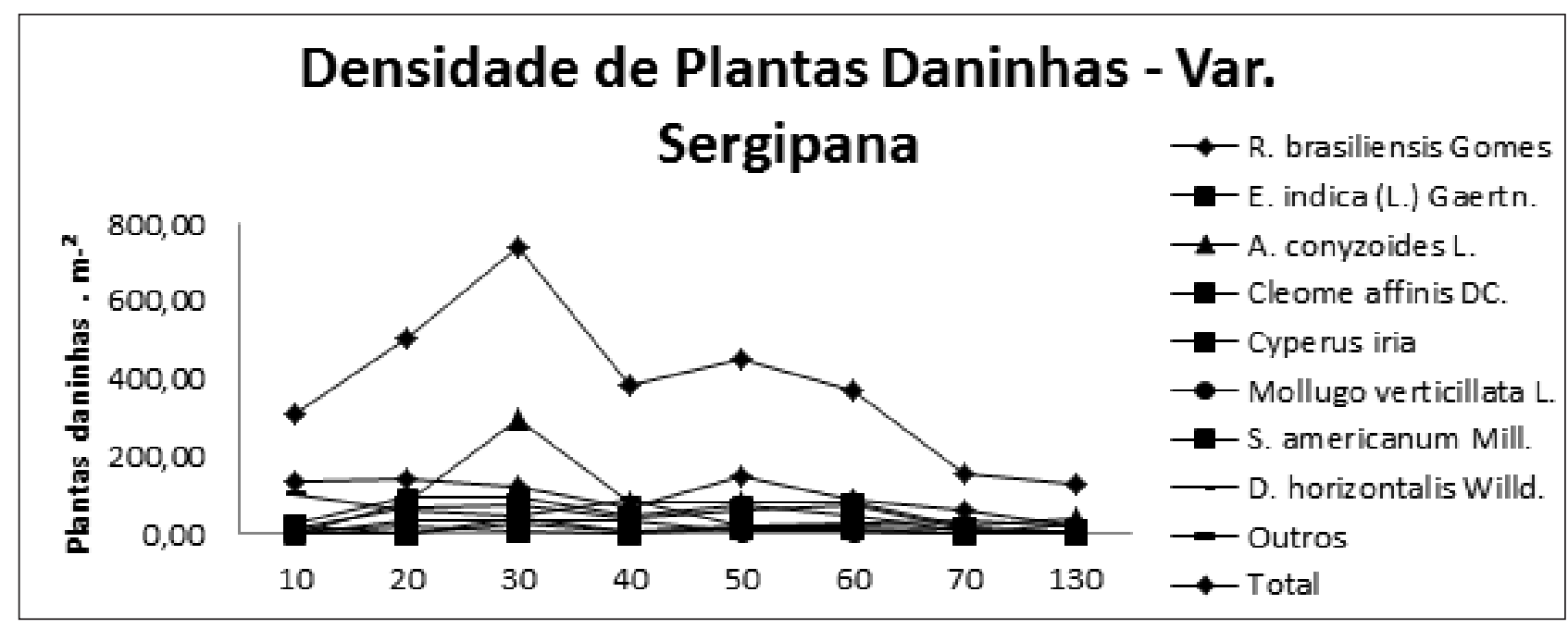

Nas parcelas cultivadas com o Clone 6 , as $\mathrm{m}^{-2}$ aos 40 DAP; Capim tapete (M. verticillata L.), com espécies de plantas daninhas de maiores densidades, como 0 Mentrasto (A. conyzoides L.), também apresentaram a maior densidade com 272 plantas $\mathrm{m}^{-2}$ aos 20 DAP; seguido pelo Capim-pé-de-galinha ( $E$. indica (L.) Gaertn.), com 153 plantas $\mathrm{m}^{-2}$ aos $30 \mathrm{DAP}$; Poaia branca (R. brasiliensis Gomes), com 130 plantas 102,67 plantas $\mathrm{m}^{-2}$ aos 30 DAP; Tiririca (C. iria L.), com 81,33 plantas $\mathrm{m}^{-2}$ aos 50 DAP, Maria Pretinha ( $S$. americanum Mill.) com 42,67 plantas $\mathrm{m}^{-2}$ aos 20 DAP, Mussambê (C. affinis DC.) com 28,00 plantas $\mathrm{m}^{-2}$ aos 70 DAP e Capim Colchão (D. horizontalis Willd.) com 10,67 plantas $\mathrm{m}^{-2}$ aos 40 DAP (Figura 3).

Figura 3. Densidade total e densidade das principais plantas daninhas infestantes (plantas $m-2$ ) em função dos períodos de convivência com o genótipo de batata-doce em dias após o plantio (DAP) (Clone 6). Rio Largo - AL, 2013.

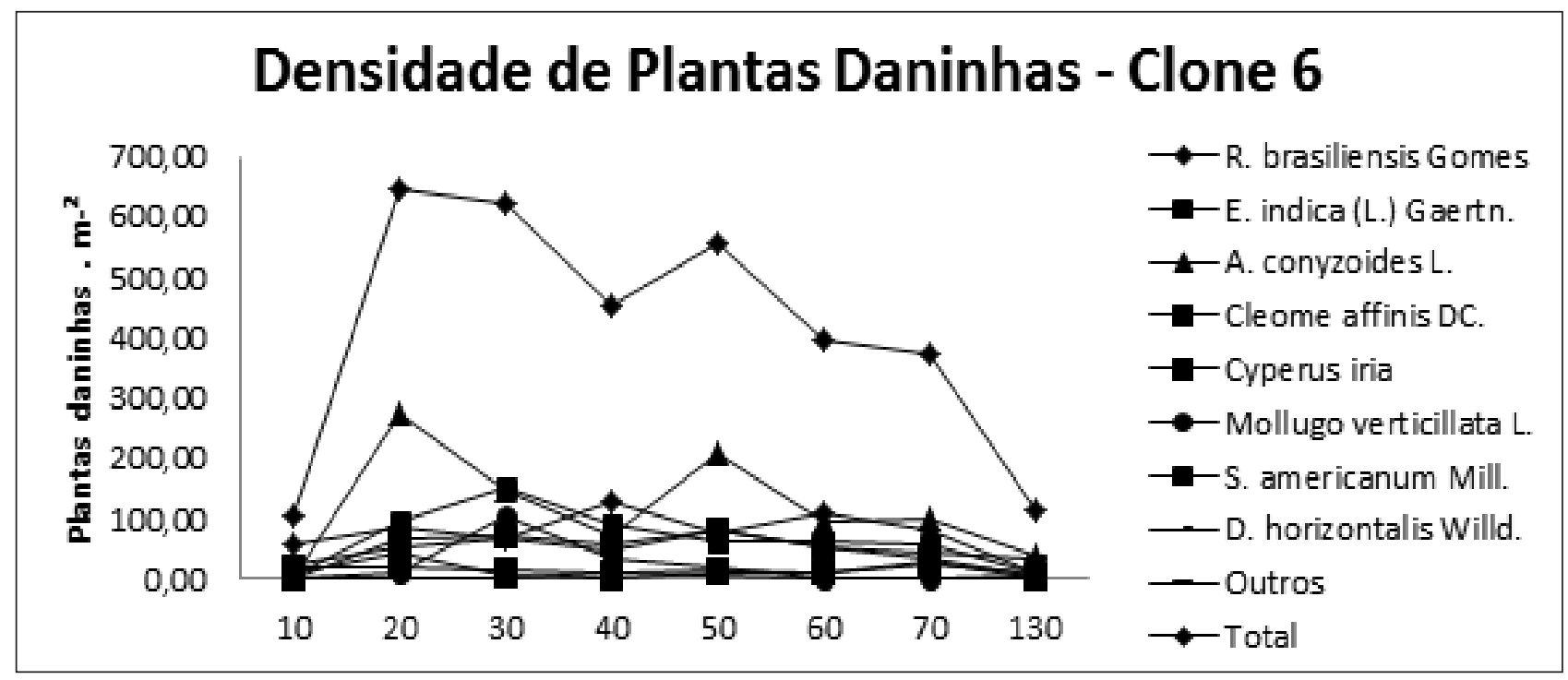

As espécies de plantas daninhas com maior expressão nas parcelas cultivadas com o Clone 14 com relação à densidade foram: Poaia branca $(R$. brasiliensis Gomes), com 232 plantas $\mathrm{m}^{-2}$ aos $20 \mathrm{DAP}$; Mentrasto ( $A$. conyzoides L.), com 210 plantas $\mathrm{m}^{-2}$ aos 20 DAP, e 224 plantas $\mathrm{m}^{-2}$ aos 30 DAP; Capim-pé-de-galinha (E. indica (L.) Gaertn.), com 86,67 plantas $\mathrm{m}^{-2}$ aos 30 e 85,33 plantas $\mathrm{m}^{-2}$ aos 40 DAP; Tiririca (C. iria L.), com 65,33 plantas $\mathrm{m}^{-2}$ aos 50 DAP; Capim tapete (M. verticillata L.), com 52 plantas $\mathrm{m}^{-2}$ aos 30 DAP, Maria Pretinha (S. americanum Mill.) com 44,00 plantas $\mathrm{m}^{-2}$ aos 20 e 36 plantas $\mathrm{m}^{-2}$ aos 50 DAP, Mussambê(C. affinis DC.) com 21,33 plantas $\mathrm{m}^{-2}$ aos 10 DAP e Capim Colchão (D. horizontalis Willd.) com 16,00 plantas $\mathrm{m}^{-2}$ aos 70 DAP (Figura 4). 
Figura 4. Densidade total e densidade das principais plantas daninhas infestantes (plantas $m-2$ ) em função dos períodos de convivência com o genótipo de batata-doce em dias após o plantio (DAP) (Clone 14). Rio Largo - AL, 2013.

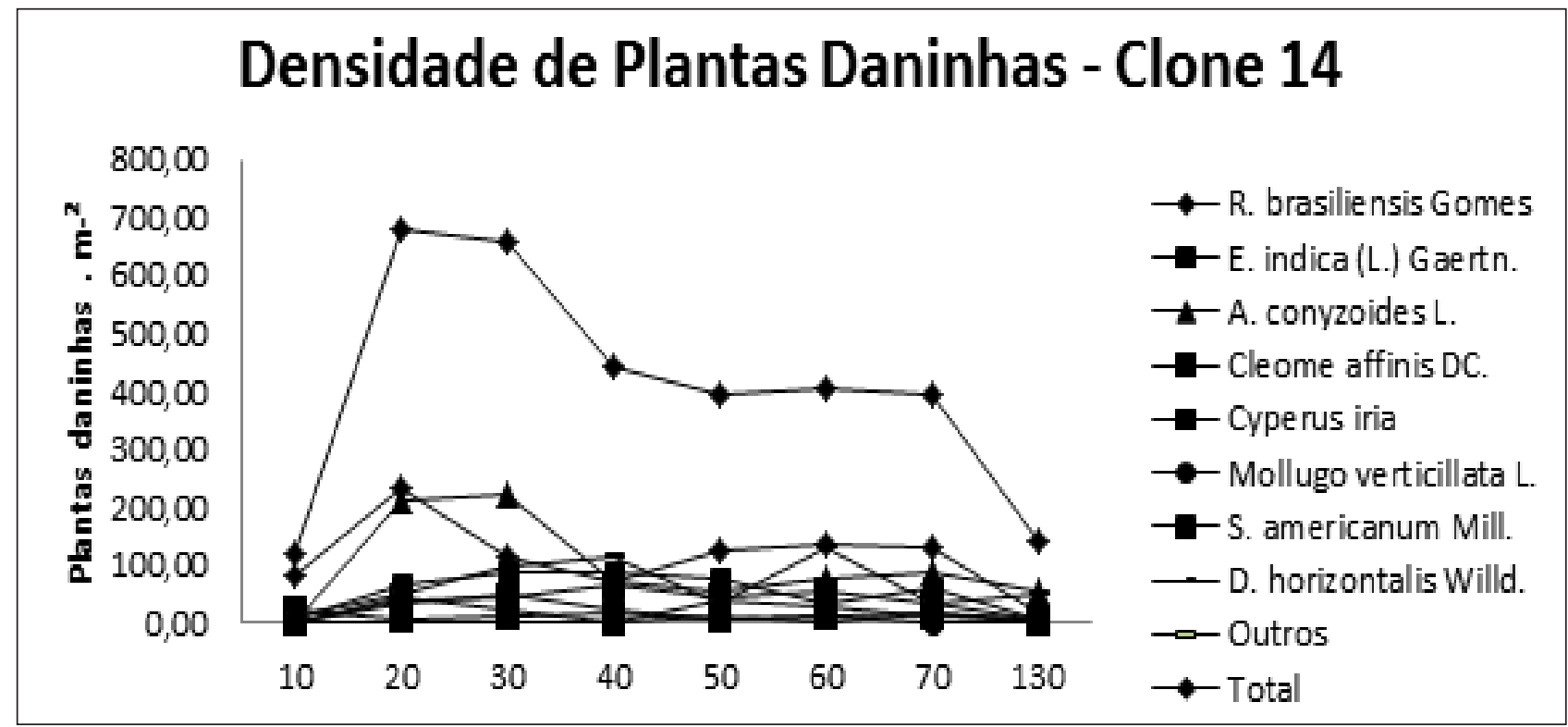

Estudos realizados por Freitas et al. (2009), analisando a interferência de plantas daninhas na cultura da cenoura em períodos iniciais de controles, verificaram que as plantas daninhas que se destacaram foram: Commelina. benghalensis com $21,79 \%$, seguida pelo Talinum paniculatum com 19,69\% e Phyllantus tenellus com 16,80\%. Trabalhos realizados por Coelho et al. (2009), estudando interferência de plantas daninhas na cultura da cenoura, observaram que a espécie A. conyzoides foi a mais importante quanto a densidade nos períodos de convivência; aos 42 dias após a semeadura (DAS), a importância relativa da espécie foi maior que $50 \%$ e a espécie $E$. indica foi a segunda mais importante, destacandose mais em função da densidade populacional, da mesma maneira que Digitaria nuda, a terceira espécie mais importante. Nos períodos no limpo, A. conyzoides também foi a espécie com maior importância relativa e a $D$. nuda foi a segunda espécie mais importante, enquanto $E$. indica foi a terceira, ambas destacando-se mais em função do número de indivíduos. Costa, et al. (2008), estudando a interferência de plantas daninhas na cultura da batata ( $S$. tuberosum) observaram que a comunidade de plantas daninhas atingiu as maiores densidades a partir dos 14 DAP (249 plantas $\mathrm{m}^{-2}$ ) e aos 28 DAP (433 plantas $\mathrm{m}^{-2}$ ), para os períodos de controle e de convivência, respectivamente. Costa, et al. (2013), verificando o período de interferência de plantas daninhas na cultura da mandioca, verificaram que as maiores densidades das plantas daninhas foram atingidas aos 150 DAP (50 plantas $\mathrm{m}^{-2}$ ) e aos 75 DAP (114 plantas $\mathrm{m}^{-2}$ ), para os períodos de controle e de convivência, respectivamente.

\section{Massa seca}

A massa seca total das plantas daninhas obteve comportamento crescente ao longo de todo o ciclo dos genótipos de batata-doce (Figura 5). Aos 30 DAP, as plantas daninhas apresentaram baixo acúmulo de massa seca. Após este período houve um acúmulo significativo, chegando ao final do ciclo (aos 130 DAP) com valores de 778,69, 654,56 e 517,96 gramas $\mathrm{m}^{-2}$ nas áreas das parcelas cultivadas com o Clone 14, variedade Sergipana e 0 Clone 6, respectivamente. 
Figura 5. Massa seca total das plantas daninhas infestantes (gramas m-2) em função dos períodos de convivência com genótipos de batata-doce em dias após o plantio (DAP). Rio Largo - AL, 2013

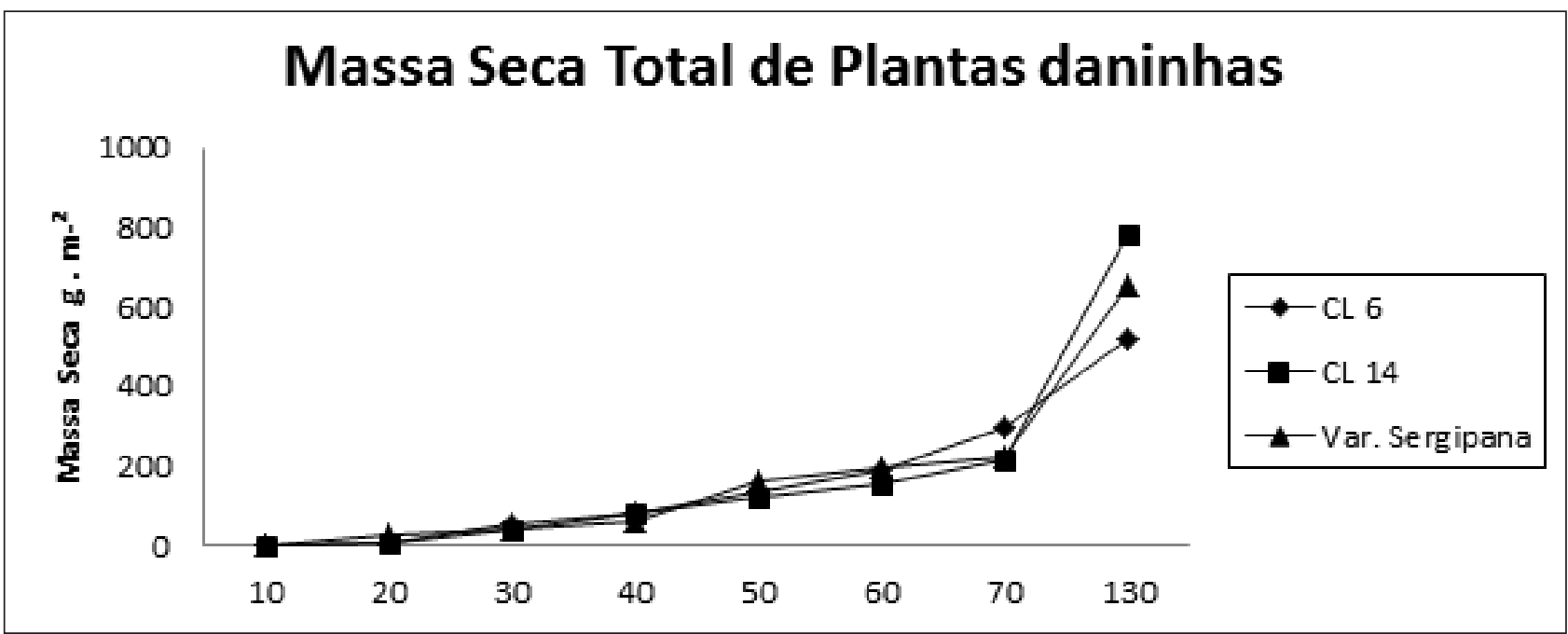

Os resultados de matéria seca das plantas daninhas do presente artigo corroboram com os encontrados por Freitas et al. (2009), que estudando a interferência de plantas daninhas na cultura da cenoura, notaram que os maiores valores de massa seca acumulada foi verificado no final do ciclo da cultura para os períodos iniciais de controle, havendo predominância de plantas anuais de ciclo longo, com alta taxa de crescimento inicial e com maior altura, como A. spinosus, que, mesmo com $11,30 \%$ da densidade total, foi responsável por mais de 55\% da massa seca total das plantas daninhas. Já Coelho et al. (2009), por sua vez, o acúmulo de massa seca das plantas daninhas na cultura da cenoura mostrou tendência crescente até 80 DAS $\left(2.439,45 \mathrm{~g} \mathrm{~m}^{-2}\right)$. Esse comportamento é típico de comunidades infestantes de agroecossistemas, pois, segundo Radosevich et al. (2007), à medida que aumenta a densidade populacional e ocorre 0 desenvolvimento das plantas daninhas, as competições intra e interespecífica intensificam-se, permitindo que as plantas mais altas e desenvolvidas tornem-se dominantes, enquanto as plantas menores e menos desenvolvidas são suprimidas ou mortas. Segundo Brighenti et al. (2004), o acúmulo total de massa seca pode ser considerado indicador mais confiável do que a população de plantas daninhas, no tocante ao grau de competição imposto à cultura.

O acúmulo máximo de massa seca das plantas daninhas nas áreas das parcelas com a variedade Sergipana foi verificada aos 130 DAP para as espécies Mentrasto (A. conyzoides $\mathrm{L}$ ) e
Poaia branca ( $R$. brasiliensis Gomes) com valores de 113,64 e 95,75 gramas $\mathrm{m}^{-2}$ respectivamente (Figura 6). Nas áreas cultivadas com o Clone 6, o maior acúmulo de massa seca ocorreu aos 60 DAP para a espécie Poaia branca ( $R$. brasiliensis Gomes) com 94,84 gramas $m^{-2}$ e também aos 130 DAP com as espécies Mentrasto ( $A$. conyzoides $L$ ) e Poaia branca (R. brasiliensis Gomes) com 105,35 e 66,48 gramas $\mathrm{m}^{-2}$, respectivamente (Figura 7). Nas áreas cultivadas do Clone 14, as espécies que se destacaram foram: Poaia branca ( $R$. brasiliensis Gomes) aos 70 DAP com102,45 gramas $m-2$, Maria pretinha ( $S$. americanum Mill.) e Mentrasto (A. conyzoides $L$ ) aos 130 DAP com valores de 135,37 e 110,34 gramas $\mathrm{m}^{-2}$, respectivamente. (Figura 8).

Silva et al. (2013), estudando os períodos de interferências de plantas daninhas na cultura do girassol, verificaram que a espécie Urocloa. plantaginea acumulou maior massa seca aos 49 e 110 dias com 47,2 e 220,86 $\mathrm{g} \mathrm{m}^{-2}$ respectivamente, nos períodos de convivência, seguido pela espécie Raphanus raphanistrum com maior acúmulo de massa seca aos 42 dias $\left(76,76 \mathrm{~g} \mathrm{~m}^{-2}\right)$. Para os períodos de controle, a espécie daninha $C$. benghaliensis apresentou o maior acúmulo de massa seca aos 7, 14 e 21 DAE, correspondente a 1,72, 1,57 e $1,36 \mathrm{~g} \mathrm{~m}^{-2}$, respectivamente. Freitas et al. (2009), também estudando a interferência de plantas daninhas na cultura da cenoura em períodos iniciais de controles, verificaram que a espécie daninhas $A$. spinosus se destacou com mais de $55 \%$ da massa seca acumulada. 
Figura 6. Massa seca total e das principais plantas daninhas infestantes (gramas $\mathrm{m}-2$ ) em função dos períodos de convivência com a variedade de batata-doce Sergipana em dias após o plantio (DAP). Rio Largo - AL, 2013.

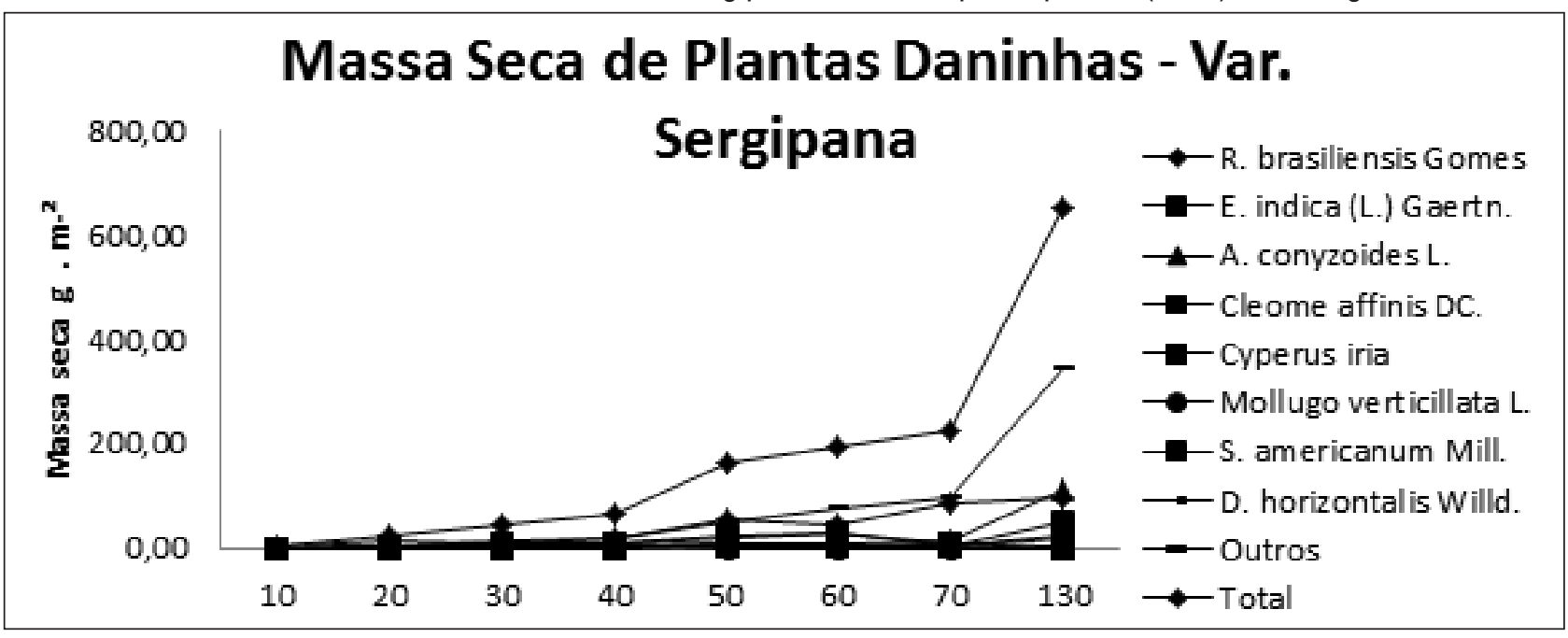

Figura 7. Massa seca total e das principais plantas daninhas infestantes (gramas $\mathrm{m}-2$ ) em função dos períodos de convivência com a o genótipo de batata-doce (Clone 6) em dias após o plantio (DAP). Rio Largo - AL, 2013

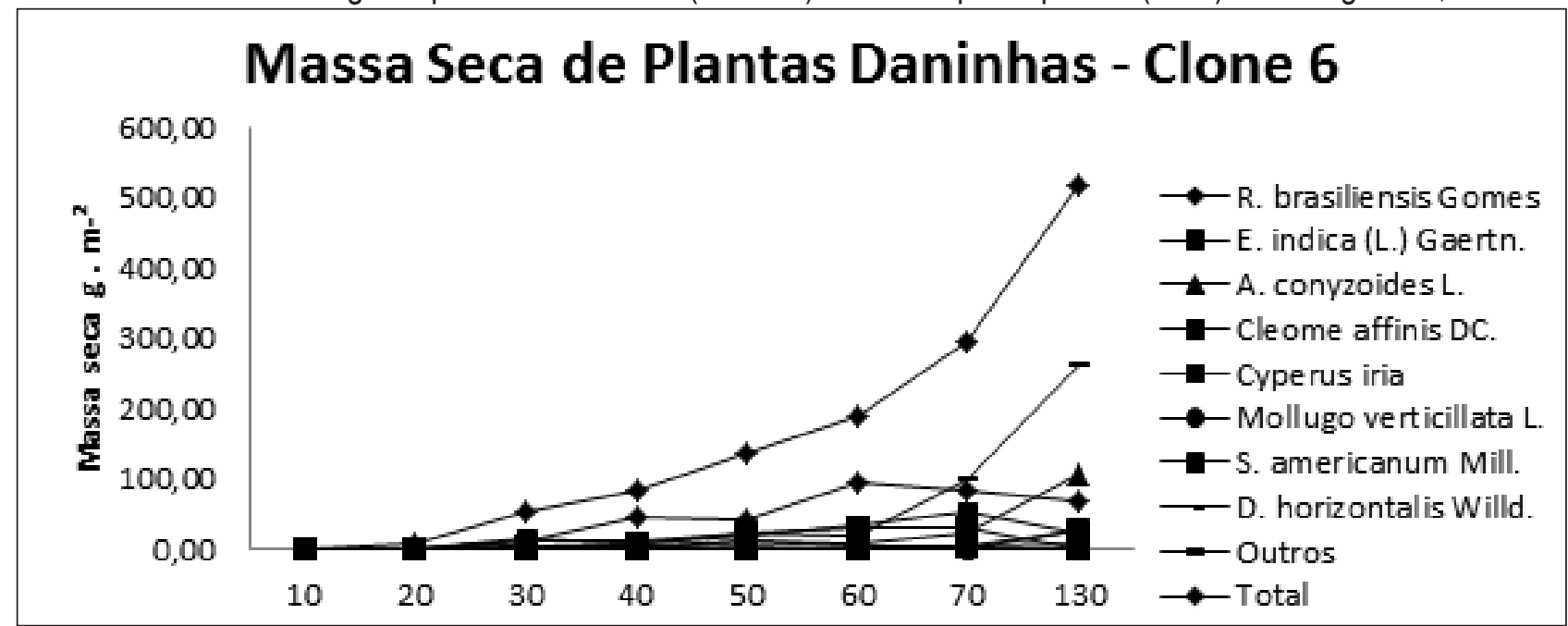

Figura 8. Massa seca total e das principais plantas daninhas infestantes (gramas $\mathrm{m}-2$ ) em função dos períodos de convivência com a o genótipo de batata-doce (Clone 14) em dias após o plantio (DAP). Rio Largo - AL, 2013.

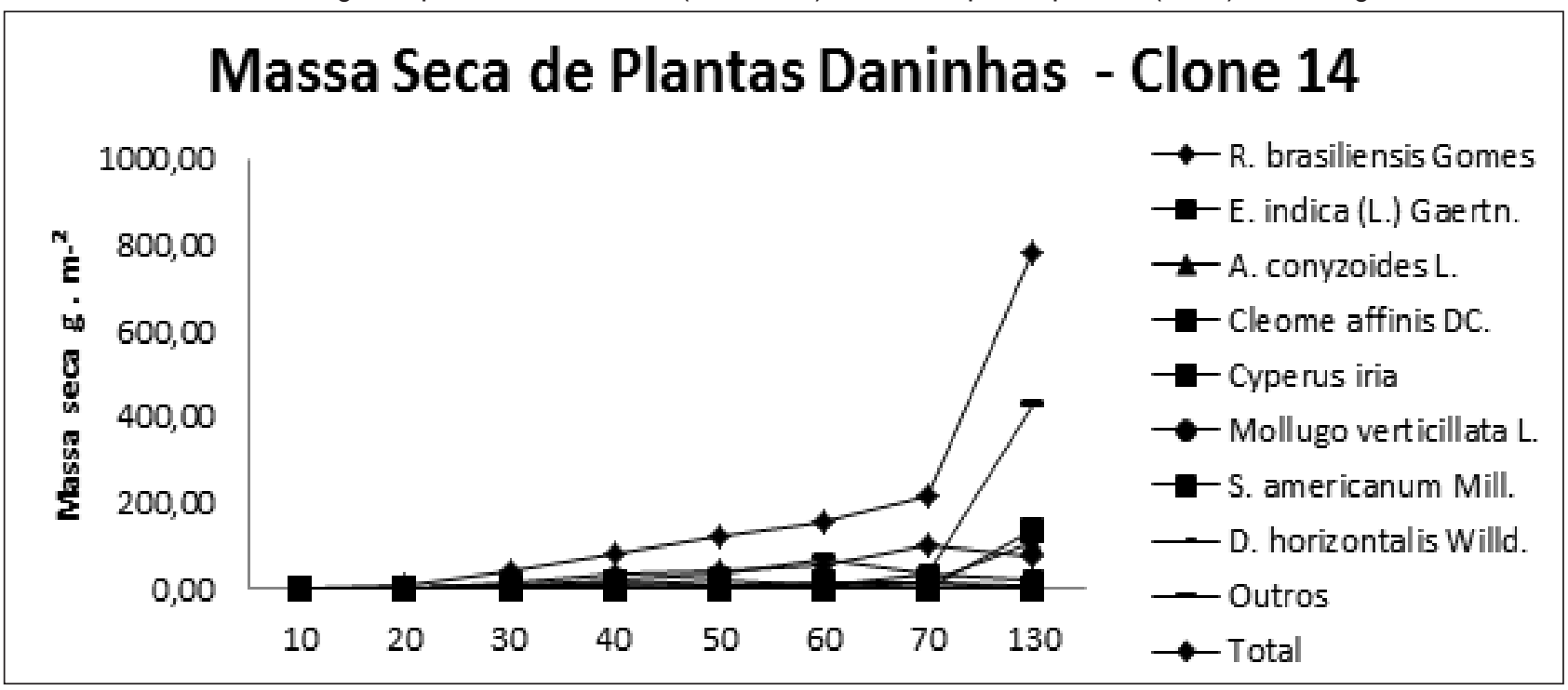


As espécies de plantas daninhas com maior expressão nas parcelas cultivadas com o Clone 14 com relação à densidade foram: Poaia branca $(R$. brasiliensis Gomes), com 232 plantas $\mathrm{m}^{-2}$ aos 20 DAP; Mentrasto ( $A$. conyzoides L.), com 210 plantas $\mathrm{m}^{-2}$ aos 20 DAP, e 224 plantas m-2 aos 30 DAP; Capim-pé-degalinha (E. indica (L.) Gaertn.), com 86,67 plantas $\mathrm{m}^{-2}$ aos 30 e 85,33 plantas $\mathrm{m}^{-2}$ aos 40DAP; Tiririca (C. iria L.), com 65,33 plantas $\mathrm{m}^{-2}$ aos 50 DAP.

Até os 30 DAP, as plantas daninhas apresentaram baixo acúmulo de massa seca. Só após este período houve um acúmulo significativo, chegando ao final do ciclo (aos 130 DAP) com valores de 778,69, 654,56 e 517,96 gramas $\mathrm{m}^{-2}$ nas áreas das parcelas cultivadas com 0 Clone 14, variedade Sergipana e o Clone 6, respectivamente, cujas diferenças podem ser atribuídas as características morfofisiológicas dos genótipos.

0 acúmulo máximo de massa seca das plantas daninhas nas áreas das parcelas com a variedade Sergipana foi verificada aos 130 DAP para as espécies Mentrasto (A.conyzoides L) e Poaia branca $(R$. brasiliensis Gomes) com valores de 113,64 e 95,75 gramas $\mathrm{m}^{-2}$ respectivamente (Figuras 6 ).

Nas áreas cultivadas com o Clone 6, o maior acúmulo de massa seca ocorreu aos 60 DAP para a espécie Poaia branca ( $R$. brasiliensis Gomes) com 94,84 gramas $\mathrm{m}^{-2}$ e também aos 130 DAP com as espécies Mentrasto ( $A$. conyzoides $L$ ) e Poaia branca (R. brasiliensis Gomes) com 105,35 e 66,48 gramas $\mathrm{m}^{-2}$, respectivamente (Figuras 7 ).

Nas áreas cultivadas do Clone 14, as espécies que se destacaram foram: Poaia branca $(R$. brasiliensis Gomes) aos 70 DAP com 102,45 gramas $\mathrm{m}^{-2}$, Maria pretinha ( $S$. americanum Mill.) e Mentrasto ( $A$. conyzoides $L$ ) aos 130 DAP com valores de 135,37 e 110,34 gramas $\mathrm{m}^{-2}$, respectivamente. (Figuras 8 ).

\section{Parâmetros fitossociológicos:}

A partir da identificação das espécies de plantas daninhas, foram determinados os parâmetros fitossociológicos com base na massa seca e densidade: massa seca relativa, densidade relativa, frequência, frequência relativa, abundância, abundância relativa e índice de valor de importância, para os genótipos de batata-doce aos 30, 70 e aos 130 DAP (MUELLERDOMBOIS e ELLENBERG, 1974).
Na área cultivada com o Clone 6, aos $30 \mathrm{DAP}$, foram identificadas 23 espécies, das quais $E$. indica (L.) Gaertn. (Capim-pé-de-galinha) e R. grandiflora Cham. \& Schltdl. (Poaia branca) apresentaram as maiores percentagens de matéria seca acumulada, com 27,67 e 21,30\%, respectivamente; quanto à densidade, os maiores valores foram observados nas espécies $A$. conyzoides L. (Mentrasto), $E$. indica (L.) Gaertn. (Capim-pé-de-galinha) e R. grandiflora Cham. e Schltdl. (Poaia branca), com 139,56, 84,36 e 68,17 plantas $\mathrm{m}^{-2}$, respectivamente; as maiores frequências $(100 \%)$ foram observadas nas espécies $R$. grandiflora Cham. \& Schltdl. (Poaia branca), E. indica (L.) Gaertn. (Capim-pé-de-galinha) e C. affinis DC. (Mussambê); as espécies que apresentaram as maiores abundâncias foram A. conyzoides L. (Mentrasto), E. indica (L.) Gaertn. (Capim-pé-de-galinha) e R. grandiflora Cham. \& Schltdl. (Poaia branca), com valores de 46,52; 28,15 e 23,11, respectivamente, já para o IVI, as espécies $R$. grandiflora Cham. \& Schltdl. (Poaia branca), E. indica (L.) Gaertn. (Capim-pé-de-galinha) e A. conyzoides L. (Mentrasto) apresentaram os maiores índices com 22,86, 13,48 e 13,00\%, respectivamente.

Aos 70 DAP, foram identificadas 26 espécies, sendo a R. grandiflora Cham. \& Schltdl. (Poaia branca) a que apresentou maior percentagem de matéria seca acumulada, 37,88\%; quanto à densidade, os maiores valores foram observados nas espécies $A$. conyzoides L. (Mentrasto), R. grandiflora Cham. \& Schltdl. (Poaia branca), e E. indica (L.) Gaertn. (Capimpé-de-galinha), com 118,00, 100,17, 67,00 plantas $\mathrm{m}^{-2}$, respectivamente; as maiores frequências $(100 \%)$ foram observadas nas espécies $R$. grandiflora Cham. \& Schltdl. (Poaia branca), E. indica (L.) Gaertn. (Capimpé-de-galinha), A. conyzoides L. (Mentrasto) e C. iria L. (Tiririca-de-brejo); as espécies que apresentaram as maiores abundâncias foram $A$. conyzoides $L$. (Mentrasto), R. grandiflora Cham. \& Schltdl. (Poaia branca), E. indica (L.) Gaertn. (Capim-pé-de-galinha) e C. iria L. (Tiririca-de-brejo) com valores de 39,33; 33,39; 22,33 e 18,78, respectivamente, já para o IVI, as espécies $R$. grandiflora Cham. \& Schltdl. (Poaia branca), E. indica (L.) Gaertn. (Capim-pé-de-galinha) e A. conyzoides $L$. (Mentrasto) apresentaram os maiores índices, com 23,05, 15,34 e 12,92\%, respectivamente.

Já aos 130 DAP, foram identificadas 18 espécies, destas, o A. conyzoides L. (Mentrasto), - Galinoga parviflora Cav. (Picão branco) e a 
R. grandiflora Cham. \& Schltdl. (Poaia branca) destacaram-se com as maiores percentagens de matéria seca, 20,32, 14,03 e 12,28\%, respectivamente; quanto à densidade, a espécie $A$. conyzoides $\mathrm{L}$. (Mentrasto) apresentou a maior expressão com 40,57 plantas $\mathrm{m}^{-2}$; a maior frequência (100\%) foi observada na espécie $A$. conyzoides L. (Mentrasto); as espécies que apresentaram as maiores abundâncias foram $A$. conyzoides L. (Mentrasto), Lindernia crustaceae (L.) F. Muell (Douradinha-do-pará), com valores de 5,80 e 4,89, respectivamente, e para o IVI, a espécie $A$. conyzoides $L$. (Mentrasto) também apresentou o maior índice com 21,62\%.

A área cultivada com o Clone 14, aos $30 \mathrm{DAP}$, apresentou 19 espécies de plantas daninhas, sendo a $R$. grandiflora Cham. \& Schltdl. (Poaia branca) a que apresentou o maior percentual de matéria seca, com $33,29 \%$; quanto a densidade, os maiores valores foram observados nas espécies $A$. conyzoides L. (Mentrasto), R. grandiflora Cham. \& Schltdl. (Poaia branca) e E. indica (L.) Gaertn. (Capim-pé-de-galinha), com $145,27,138,73$ e 52,18 plantas $\mathrm{m}^{-2}$, respectivamente; as maiores frequências $(100 \%)$ foram observadas nas espécies $R$. grandiflora Cham. \& Schltdl. (Poaia branca) e C. affinis DC. (Mussambê); as espécies que apresentaram as maiores abundâncias foram A. conyzoides L. (Mentrasto), R. grandiflora Cham. \& Schltdl. (Poaia branca) e E. indica (L.) Gaertn. (Capim-pé-de-galinha) com valores de 48,44; 47,56 e 17,48, respectivamente; já para o IVI, as espécies $R$. grandiflora Cham. \& Schltdl. (Poaia branca) e A. conyzoides L. (Mentrasto) apresentaram os maiores índices com 32,48 e 14,33\%, respectivamente.

Aos 70 DAP, identificou-se 25 espécies, sendo R. grandiflora Cham. \& Schltdl. (Poaia branca) a que apresentou maior percentagem de matéria seca acumulada, 39,81\%; quanto à densidade, os maiores valores foram observados nas espécies R. grandiflora Cham. \& Schltdl. (Poaia branca), A. conyzoides L. (Mentrasto), e E. indica (L.) Gaertn. (Capim-pé-de-galinha), com 115,67, 73,00, 63,33 plantas $\mathrm{m}^{-2}$, respectivamente; as maiores frequências $(100 \%)$ foram observadas nas espécies $R$. grandiflora Cham. \& Schltdl. (Poaia branca), A. conyzoides L. (Mentrasto), C. affinis DC. (Mussambê), E. indica (L.) Gaertn. (Capim-pé-de-galinha) e C. iria L. (Tiriricade-brejo); as espécies que apresentaram as maiores abundâncias foram $R$. grandiflora Cham. \& Schltdl.
(Poaia branca), A. conyzoides L. (Mentrasto), E. indica (L.) Gaertn. (Capim-pé-de-galinha) e C. iria L. (Tiriricade-brejo), com valores de 38,56; 24,33; 21,11 e 16,28, respectivamente; e para o IVI, a espécie $R$. grandiflora Cham. \& Schltdl. (Poaia branca) apresentou o maior índice, com 24,95\%.

Já aos 130 DAP, foram identificadas 19 espécies, destas, a S. americanum Mill. (Maria pretinha), 0 A. conyzoides L. (Mentrasto), o Physalis angulata L. (Balão), a G. parviflora Cav. (Picão branco), a Merremia cissoides (L.) Hallier f. (Jitirana) e a R. grandiflora Cham. \& Schltdl. (Poaia branca) apresentaram as maiores percentagens de matéria seca acumulada, com 17,38; 14,$17 ; 13,14 ; 11,18 ; 10,13$ e 9,41\%, respectivamente quanto à densidade, a espécie $A$. conyzoides $\mathrm{L}$. (Mentrasto) apresentou a maior expressão com 53,14 plantas $\mathrm{m}^{-2}$; a maior frequência $(100 \%)$ foi observada para a espécie $A$. conyzoides $L$. (Mentrasto); as espécies que apresentaram as maiores abundâncias foram A. conyzoides L. (Mentrasto), L. crustaceae (L.) F. Muell (Douradinha-do-pará), com valores de 7,59 e 3,84 respectivamente; e já para o IVI, a espécie $A$. conyzoides $\mathrm{L}$. (Mentrasto) também apresentou o maior índice com 21,98\%.

$\mathrm{Na}$ área cultivada com a variedade Sergipana, aos 30 DAP, foram identificadas 22 espécies de plantas daninhas, sendo a $R$. grandiflora Cham. \& Schltdl. (Poaia branca) a que apresentou a maior percentagem de matéria seca, 25,09\%; quanto à densidade, os maiores valores foram observados nas espécies $A$. conyzoides L. (Mentrasto), $R$, grandiflora Cham. \& Schltdl. (Poaia branca) e E. indica (L.) Gaertn. (Capim-pé-de-galinha), com 124,59; 101,90 e 65,71 plantas $\mathrm{m}^{-2}$, respectivamente; as maiores frequências (100\%) foram observadas nas espécies $R$. grandiflora Cham. \& Schltdl. (Poaia branca) e C. affinis DC. (Mussambê); as espécies que apresentaram as maiores abundâncias foram $R$. grandiflora Cham. \& Schltdl. (Poaia branca), A. conyzoides L. (Mentrasto), E. indica (L.) Gaertn. (Capim-pé-de-galinha) e C. iria L. (Tiririca-de-brejo), com valores de 43,85; 41,63; 24,00 e 17,33, respectivamente; e para o IVI, as espécies R. grandiflora Cham. \& Schltdl. (Poaia branca) e A. conyzoides L. (Mentrasto) apresentaram os maiores índices com 22,55 e 12,58\%, respectivamente.

Aos 70 DAP, identificou-se 24 espécies, sendo a R. grandiflora Cham. \& Schltdl. (Poaia branca) a que apresentou maior percentagem de matéria 
seca acumulada, 32,02\%; quanto à densidade, os maiores valores foram observados nas espécies R. grandiflora Cham. \& Schltdl. (Poaia branca) e A. conyzoides L. (Mentrasto), com 92,00 e 68,17 plantas $\mathrm{m}^{-2}$, respectivamente; as maiores frequências (100\%) foram observadas nas espécies $R$. grandiflora Cham. \& Schltdl. (Poaia branca), A. conyzoides L. (Mentrasto), E. indica (L.) Gaertn. (Capim-pé-de-galinha) e C. iria L. (Tiririca-de-brejo); as espécies que apresentaram as maiores abundâncias foram: $R$. grandiflora Cham. \& Schltdl. (Poaia branca), A. conyzoides L. (Mentrasto), C. iria L. (Tiririca-de-brejo) e E. indica (L.) Gaertn. (Capimpé-de-galinha), com valores de 30,67; 22,72; 15,56 e 14,78, respectivamente; e para o IVI, as espécies R. grandiflora Cham. \& Schltdl. (Poaia branca) e A. conyzoides L. (Mentrasto) apresentaram os maiores índices, com 23,24 e 12,58\%, respectivamente.

Já aos 130 DAP, fase final do ciclo dos genótipos de batata-doce, o Clone 6 e a variedade Sergipana apresentaram uma redução na MS das plantas daninhas em 33,5 e 16,0\%, respectivamente, e na densidade em 18,0 e 8,4\%, respectivamente, em relação ao Clone 14. A espécie $R$. grandiflora Cham. \& Schltdl. (Poaia branca) destacou-se em relação às demais, aos 30 DAP, com relação à frequência, ocorrendo em 100\% das amostras; aos 70 DAP, o destaque foi também para a espécie $R$. grandiflora Cham. \& Schltdl. (Poaia branca) e o $A$. conyzoides L. (Mentrasto), ambos com frequência de 100\%, nas áreas amostradas; e aos 130 DAP, quem se destacou com frequência de $100 \%$ nas áreas amostradas foi à espécie $A$. conyzoides $L$. (Mentrasto) e também foi a mais abundante em $67 \%$ das amostragens.

Outro índice de grande importância na avaliação fitossociológica de uma comunidade infestante é o índice de valor de importância, que retrata, de certa forma, a importância ecológica de certa espécie na comunidade, quando comparado às outras espécies nela existentes, uma vez que são utilizados valores relativos.

Na Figura 9 (A, B e C), observa-se que as espécies $R$. grandiflora Cham. \& Schltdl. (Poaia branca), A. conyzoides L. (Mentrasto) e $E$. indica (L.) Gaertn. (Capim-pé-de-galinha) foram as mais predominantes na área experimental, apresentando os maiores índices de valor de importância (IVI), em média $(73,18 ; 66,68$ e 44,07), respectivamente, aos 30, 70 e 130 DAP nas áreas cultivadas com o Clone 6; (88,04; 63,59 e 34,49), respectivamente, aos 30, 70 e 130 DAP, nas áreas cultivadas com o Clone 14; e nas áreas cultivadas com a variedade Sergipana $(77,45$; 61,62 e 36,72), respectivamente, aos 30, 70 e 130 DAP, destacando-se como as espécies que apresentaram o maior poder de competição em relação às demais espécies nas áreas cultivadas com os três genótipos de batata-doce podendo ser consideradas como alvo principal para controle.

Figura 9. (A, B e C) estão demonstrados os índices de valor de importância (IVI) das principais plantas daninhas presentes aos 30, 70 e 130 dias após o plantio (DAP), para os períodos iniciais de controle no Clone 6, Clone 14 e variedade Sergipana. Plantas daninhas: Poaia branca ( $R$. brasiliensis Gomes), Capim-pé-de-galinha ( $E$. indica (L.) Gaertn.), Mentrasto (Ageratum conyzoides L.), Mussambê (Cleome affinis DC.), Ma Pretinha (Solanum americanum Mill.), Tiririca-de-brejo (Cyperus iria L.), Capim tapete (Mollugo verticillata L.), Picão branco (Galinoga parviflora Cav.), Douradinha-do-pará (L. crustaceae (L.) F. Muell), Beldroega (Portulaca oleraceae L.), Balão (Physalis angulata L.), Caruru (Amaranthus deflexus L.), Carrapicho-de- Carneiro (A. hispidum DC.).

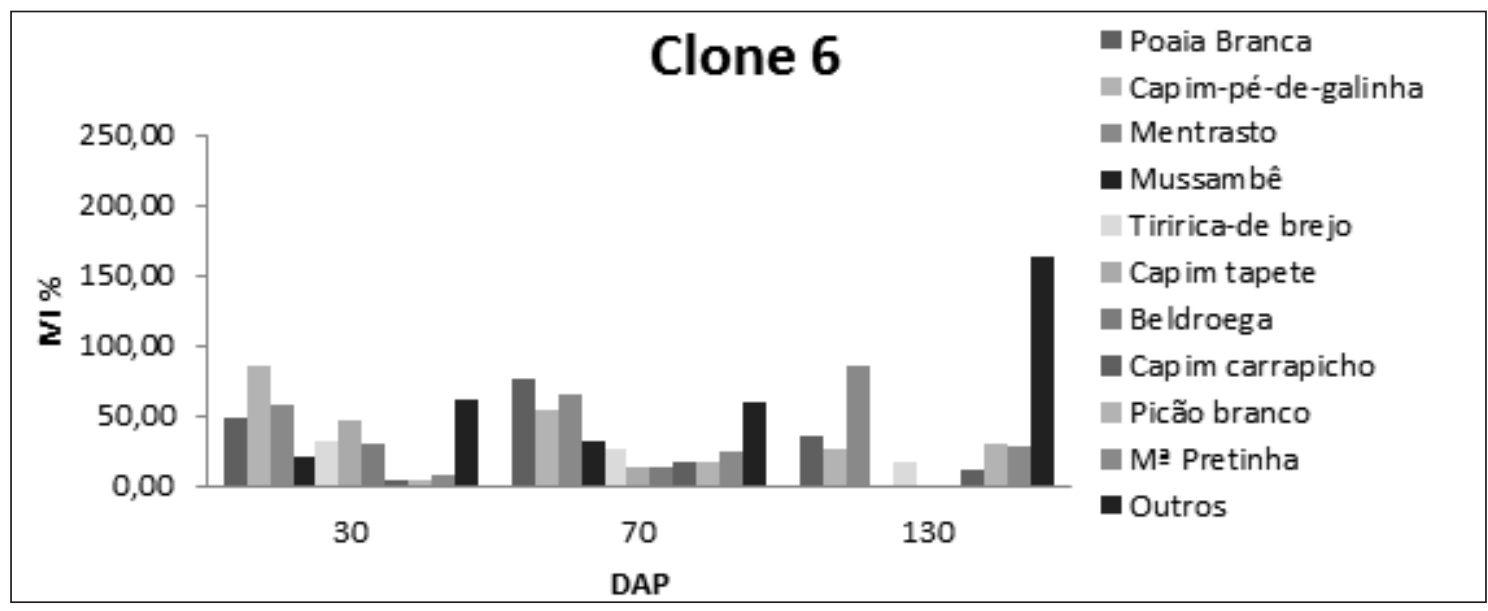



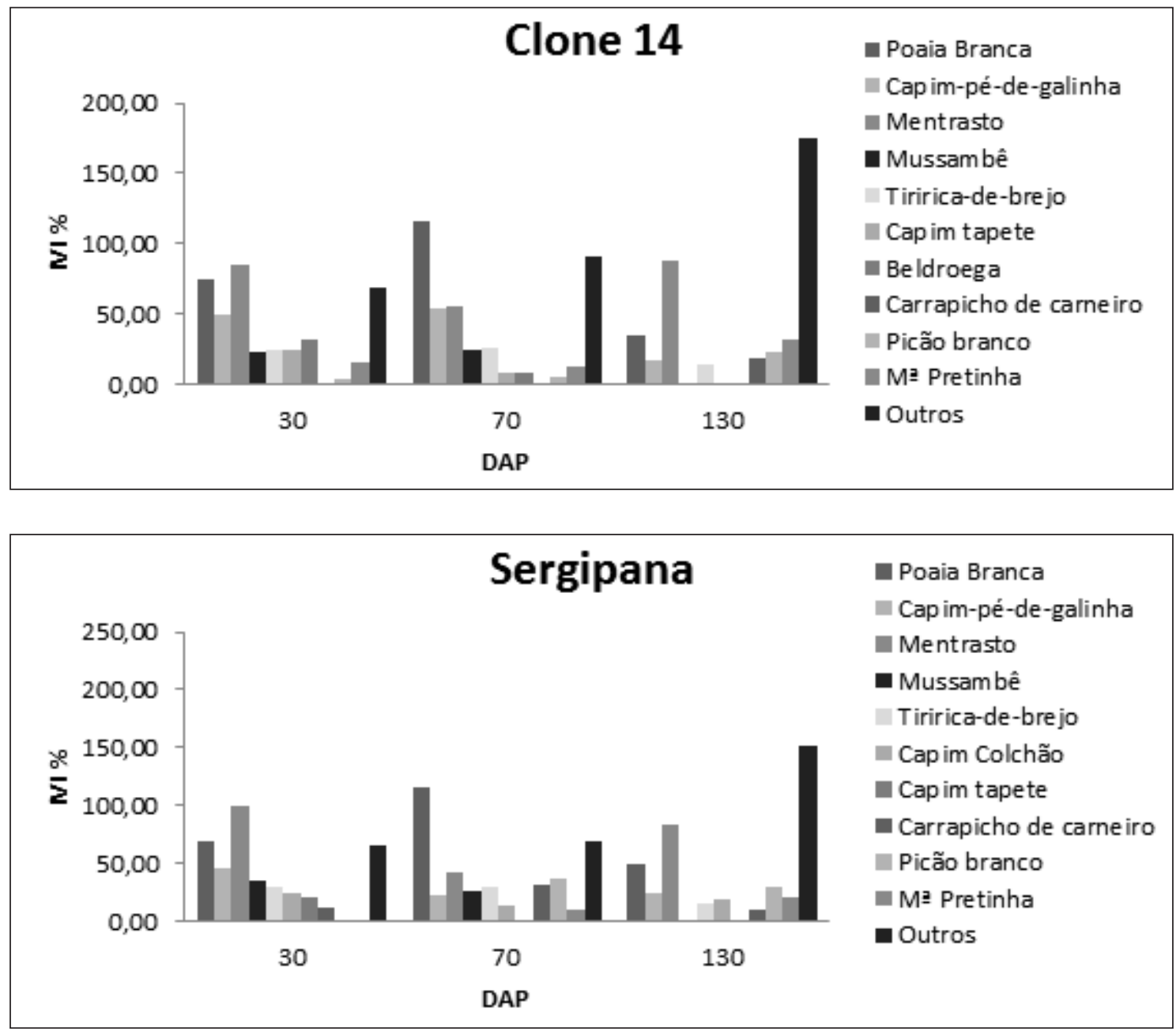

De acordo com Pitelli (1985), o grau de importância relativa das espécies infestantes presentes em um determinado local reflete o balanço dos índices fitossociológicos, sendo a avaliação mais ponderada das populações. Além disso, segundo Almendra (2005), densidades inadequadas de plantio, variedades com crescimento lento e manejo inadequado da área de plantio estão relacionados com 0 agravamento da competição exercida pelas plantas daninhas sobre a cultura.

A partir do levantamento fitossociológico é possível planejar estratégias preventivas para 0 controle sustentável de plantas daninhas existentes nas áreas cultivadas com a cultura da batata-doce, proporcionando redução nos custos de produção e impactos ambientais. No presente trabalho foram verificadas poucas espécies predominantes, apenas a R. grandiflora Cham. \& Schltdl. (Poaia branca), E. indica (L.) Gaertn. (Capim-pé-de-galinha), A. conyzoides L. (Mentrasto), Cleome affinis DC. (Mussambê), $S$. americanum Mill. (Maria pretinha) e G. parviflora Cav. (Picão branco), Isso provavelmente, pode ser atribuído ao período avaliado, tipo de solo onde foi cultivado e época de plantio, entre outros.

\section{REFERÊNCIAS BIBLIOGRÁFICAS}

ALMENDRA, A. A. Avaliação de três cultivares de mandioca de mesa (Manihot esculenta Crantz) submetidas ao controle de plantas daninhas. Dissertação (Mestrado em Agronomia) - Universidade Federal do Piauí, Teresina, 29p., 2005.

Anuário brasileiro de hortaliças 2013 - Santa Cruz do Sul: Editora Gazeta Santa Cruz. 2013, 88.

Brighenti, A. M. Castro, C.; Oliveira Junior, R.S.; Scapim, C.A.; Voll, E.; Gazziero, D.L.P. Períodos de interferência de plantas daninhas na cultura do girassol. Planta Daninha. 2004, 22, 2, 251-257.

Cavalcante, J. T.; Vanderlei, P. V.; Cunha, J. L. X. L.; Silva Júnior, A. B.; Silva; M. T.; Carvalho, I. D. E. Períodos de interferência de plantas daninhas em 
genótipos de batata-doce. Revista Cultura Agronômica. 2017, 26, 4, 640-656.

Centeno, J.A.S.; Kishi, R.T. Recursos Hídricos do Estado de Alagoas. Secretaria de Planejamento Núcleo Estadual de Meteorologia e Recursos Hídricos. 1994, 41.

Coelho, M.; Bianco, S.; Carvalho, L.B. Interferência de plantas daninhas na cultura da cenoura (Daucus carota). Planta daninha. 2009, 27, 913-920.

Costa, N.V.; Ritter, L.; Peres, E. J. L.; Silva, P. V.; Vasconcelos E.S. Períodos de interferências das plantas daninhas na variedade de mandioca Fécula Branca. Planta Daninha. 2013, 31, 533-542.

Costa, N.V.; Cardoso, L.A.; Rodrigues, A.C.P.; Martins, D. Períodos de interferência de uma comunidade de plantas daninhas na cultura da batata. Planta daninha. 2008, 26, 1, 83-91.

EMBRAPA (Empresa Brasileira de Pesquisa agropecuária) Centro Nacional de Pesquisa de Hortaliças. 2009. <http://www.cnph.embrapa.br/ cultivares/bat-doce.htm/> Acessado em: maio de 2014.

Filgueira, F. A. R. Novo manual de olericultura: agrotecnologia moderna na produção e comercialização de hortaliças. Editora UFV: Viçosa, MG, 2008, $3^{\circ} \mathrm{ed}$, $421 \mathrm{p}$.

Freitas, F. C. L.; Almeida, M. E. L.; Negreiros, M. Z.; Honorato, A. R. F.; Mesquita, H.C.; Silva, S. V. O. F. Períodos de interferência de plantas daninhas na cultura da cenoura em função do espaçamento entre fileiras. Planta daninha. 2009, 27, 3,473-480 .
IBGE - Instituto Brasileiro de Geografia e Estatística - Produção agrícola municipal vol. 40, Disponível em: ftp://ibge.gov.br/ProducaoAgricola/ProducaoAgricula Municipal[anual]/2013/tabelas_pdf/tabela02.pdf>. Acesso em: 03 fev. 2015.

Kuva, M.A.; Gravena, R.; Pitelli, R.A.; Christoffoleti, P.J. e Alves, P.L.C.A. Períodos de interferência das plantas daninhas na cultura da canade-açúcar. III - capimbraquiária (Brachiaria decumbens) e capim-colonião (Panicum maximum). Planta Daninha. 2003, 21, 1, 3744.

Mueller-dombois, D.; Ellemberg, H. Aims and methods of vegetation ecology. New York: John Willey \& Sons. 1974, 547.

Pitelli, R. A.; Pitelli, R. L. C. M. Biologia e Ecofisiologia de Plantas Daninhas. In: Vargas L.; Roman, E.S. (Org.). Manual de Manejo e Controle de Plantas Daninhas. Bento Gonçalves: EMBRAPA. 2004, 1, 29-56.

Pitelli, R. A. Interferência de plantas daninhas em culturas agrícolas. Informe Agropecuário. 1985, 11, 1627.

Radosevich, S. R.; Holt, J.; Ghersa, C. Ecology of weeds and invasive plants: relationship to agriculture and natural resource management. Editora Wiley Online Library, New York. 2007, 3ed., 454p.

Silva, R.R.; Reis, M. R.; Mendes, K.F.; Aquino, L.A.; Pacheco, D. D.; Ronchi, C.P. Períodos de interferência de plantas daninhas na cultura do girassol. Bragantina. $2013,72,3,255-261$. 